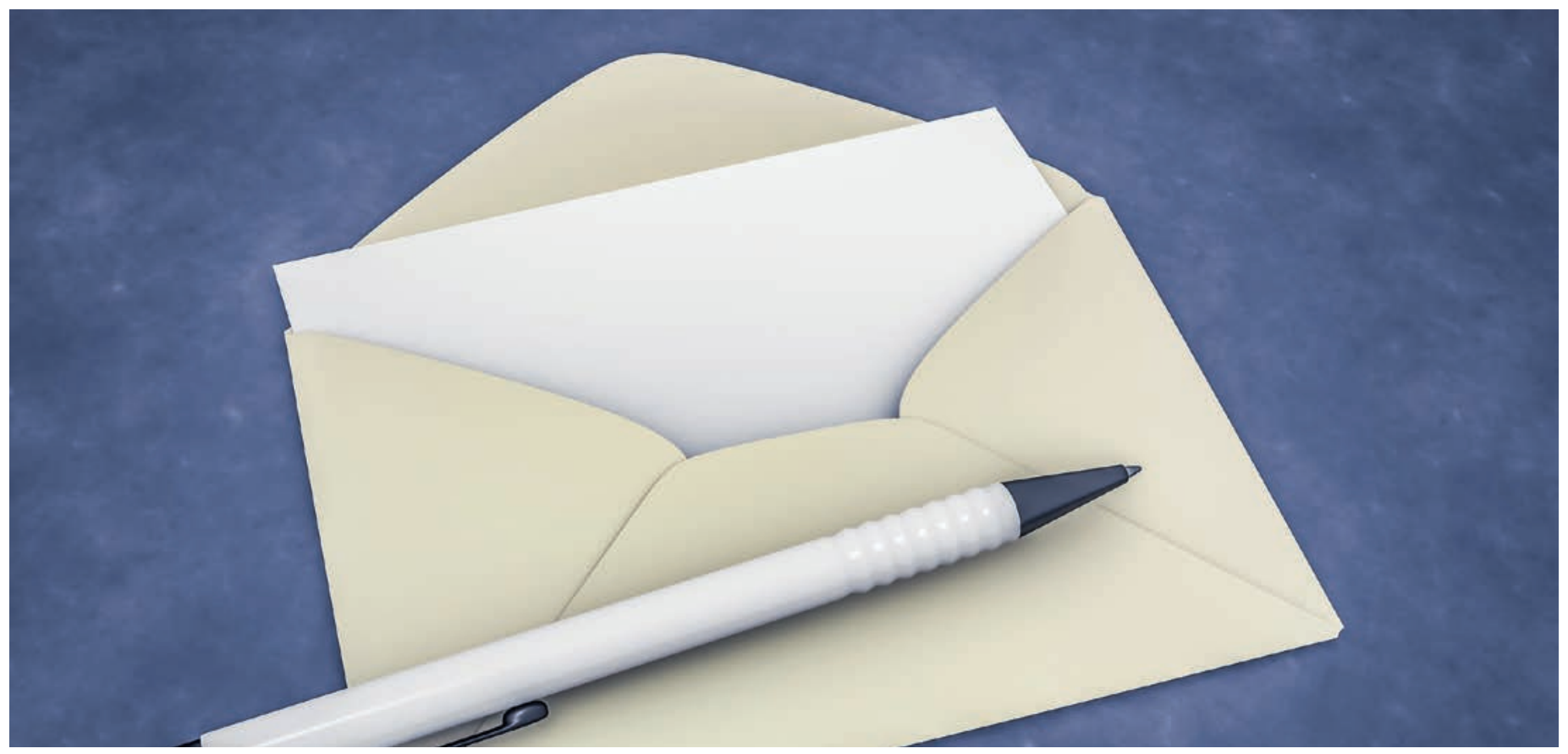

\title{
Offener Brief an die Präsidenten der Ärztegesellschaften
}

\section{Pierre Gachoud}

Dr. med. FMH für Allgemeinmedizin, Marly FR

Sehr geehrte Damen und Herren, liebe Kolleginnen und Kollegen

Arzthonorare werden in den Medien heiss diskutiert, und es wird viel darüber berichtet. Als aufmerksamer Beobachter der Entwicklungen in der Medizinpolitik erlaube ich mir in meiner Funktion als Hausarzt mit inzwischen 45 Jahren Spital- und Praxiserfahrung, an dieser Stelle einige Gedanken zum Thema zu äussern!

Seit 30 Jahren versuchte ich nun schon wiederholt, an Versammlungen der Ärztegesellschaft des Kantons Freiburg im Zusammenhang mit der Neugestaltung der ärztlichen Leistungstarife zu intervenieren.

Das erste Mal sprach ich mich gegen eine Erhöhung der Tarife für bestimmte gynäkologische Leistungen aus, mit dem Argument, dass die Vergütung meiner Kolleginnen und Kollegen aus der Gynäkologie im Schnitt um das Vierfache höher liegt als die des urbanen Gene- ralisten, der jedoch in gleicher Weise im Notfall- und im Wachdienst gefordert ist. Meine vor allem von den Kinderärzten unterstützte Intervention änderte nichts an den Fakten. Die Gynäkologen erhielten problemlos die geforderte Erhöhung.

An den TARMED-Vorverhandlungen in Bern hatte ich im Auftrag der Freiburger Generalistenabordnung auf gleiche Weise argumentiert. Ich hatte dazu noch eine nach medizinischen Fachbereichen unterteilte Vergütungstabelle zur Vorlage in der Tasche. Die Tabelle listete versteuerbares Jahreseinkommen (Vollzeit) von 90000 bis 900000 Franken in steigender Reihenfolge auf: Kinderärzte, Internisten, Generalisten, allgemeine Chirurgen, HNO, Ophthalmologen, Urologen und Gynäkologen. Nicht nur wurde ich an der Vorlage dieser Auflistung gehindert, einige Fachärzte wiesen mich ausserdem scharf zurück mit dem Argument, dass sie nicht so lange studiert hätten, um danach nur wie ein «einfacher Generalist» (!) vergütet zu werden. 
Sie hatten ihren FMH-Titel innert 6 Jahren erhalten, während ich als Generalist $8 \frac{1}{2}$ Jahre zu absolvieren hatte! Und - unter uns gesagt - wer glaubt denn wirklich, dass es Aussergewöhnliches erfordert, um Radiologe, Urologe oder Ophthalmologe zu werden?

Als TARMED verabschiedet wurde, drohten mehrere Fachgesellschaften damit, die FMH zu verlassen und Verhandlungen mit den Krankenversicherern abzulehnen. Dem FMH-Präsidenten wurde gar physische Gewalt angedroht! Ist dies hinnehmbar?

Aus Furcht vor einem Auseinanderbrechen der FMH und der Gefährdung der Gesellschaft und um kein derart katastrophales Image der Ärzteschaft nach aussen zu vermitteln, wurde TARMED dann letztlich zum Vorteil der Mehrheit der Fachärzte gestaltet, wobei sich im Grunde nichts geändert hat.

Vom Grundsatz her war man eigentlich davon ausgegangen, dass alle Ärzte mehr oder weniger gleich mit einem Honorar von durchschnittlich 200 Franken pro Stunde zu vergüten seien, da alle dieselbe Anzahl Studien- und Weiterbildungsjahre und dieselben Verantwortlichkeiten vorzuweisen haben. Der Kinderarzt steht beispielsweise ganz unten auf der Vergütungsleiter; auch er arbeitet aber 60 Stunden pro Woche, rettet das Leben von Neugeborenen und erkennt rechtzeitig eine Meningitis oder Lungenentzündung, die tödlich ausgehen kann!

Zu behaupten, Exzellenz impliziere eine grössere Verantwortung, die zu einer zusätzlichen Vergütung berechtige, ist ein echter Mythos. Wenn überhaupt, wäre ein Aufschlag von 50\% zu vertreten, aber niemals von $1000 \%$.

Der Missbrauch eines Systems, in dem die Kumulierung technischer Eingriffe im Extremfall zu einer Vergütungsdifferenz von 1 bis 10 für die Leistung eines vollzeitbeschäftigten Arztes führen, ist nicht mehr hinnehmbar. Es kann rechtlich ebenfalls nicht mehr toleriert werden, dass $10 \%$ unserer Kolleginnen und Kollegen den kantonalen Ärztegesellschaften und der FMH mit Abspaltung drohen, dass sie unseren Berufsstand schädigen, Leistungstarife nach eigenem Gusto interpretieren, echten Wert mit ihrem Bankkonto gleich- setzen und die Sitzungen unserer Berufsverbände mit ihren Launen «belasten». Warum vergeuden Sie, die Präsidenten und der Zentralvorstand dieser Ärztegesellschaften, so viel Energie darauf, dieses unzivilisierte Verhalten zu verteidigen? Vor den Medien geben Sie nicht zu, dass es Missbrauch gibt, und wiederholen in der Defensive, dass die Gesundheitskosten nicht durch die Ärzte verursacht werden, sondern Sache der Politiker, Versicherer, Patienten ... seien. Als Handelnde befinden wir uns jedoch in einer Schlüsselposition und sind insofern mitverantwortlich für die Kosten. Schon aus Rationalisierungsgründen müssen wir uns alle damit befassen!

Müssten unsere extremsten Kolleginnen und Kollegen nicht eher von der Ethikkommission sanktioniert werden, als durch eine betäubende Stille die Absolution zu erhalten?

Es wird Zeit, dass Sie sich nicht mehr von den Drohungen jener einschüchtern lassen, die geblendet sind von materiellem Komfort, denen jeglicher Gemeinschaftssinn abhandengekommen ist, die begünstigt werden durch ein ungleiches System! Vielmehr sollten Sie ein offenes Ohr haben für die weniger begünstigen Kolleginnen und Kollegen, die keine Radiologie, kein Labor haben und die keine preislich überhöhten technischen Interventionen abrechnen können, um «Kasse» zu machen.

«Leider» machen die Generalisten keinen Lärm, stellen keine Ansprüche, drohen nicht und sind absolut harmlos für unsere Mitgliederorganisationen.

Und doch sind sie der Stolz unserer Profession und gereichen ihr in aller Bescheidenheit und im Sinne unserer Pflicht, auf die wir den hippokratischen Eid abgelegt haben (was leider bei der Einführung in die Ärztegesellschaften nicht mehr der Fall ist!), zur Ehre.

Wir danken ihnen für ihre stete Verfügbarkeit und ihr Engagement, das für alle beispielhaft steht.

Freundliche Grüsse

Abbildungsnachweis

(c) Magann | Dreamstime.com 